\title{
High Spectral Brightness UV Laser for Airborne Wind-Lidar Observations
}

\author{
Oliver Lux, Christian Lemmerz, Benjamin Witschas, Uwe Marksteiner, Engelbert Nagel, Oliver Reitebuch \\ Deutsches Zentrum für Luft- und Raumfahrt (DLR), Institut für Physik der Atmosphäre, Oberpfaffenhofen 82234, Germany
}

Laser sources employed in light detection and ranging (lidar) systems for the quantification of atmospheric parameters such as wind velocity, temperature or trace gas concentration need to fulfill a large set of strict requirements regarding their power performance as well as their spatial and spectral properties. In particular, the generation of high-energy output pulses in the UV spectral region with excellent spectral purity is mandatory for the precise measurement of wind velocities by means of direct-detection Doppler wind lidar systems. Here, the frequency stability of the laser transmitter must be better than $5 \mathrm{MHz}$ to ensure low systematic errors in wind velocity of about $1 \mathrm{~m} / \mathrm{s}$. The realization of reliable, high spectral brightness laser sources is further complicated when operating in severe vibration environments such as on ships or aircraft.

Within the framework of pre-launch campaigns for the Atmospheric Dynamics Mission (ADM) Aeolus of the European Space Agency (ESA) which strives for the global observation of wind profiles from the ground to the lower stratosphere employing a satellite-borne wind lidar system (ALADIN), an airborne demonstrator (A2D) has been developed over the past years, aiming at the validation of the satellite instrument as well as at performing wind-lidar observations under various atmospheric conditions [1,2].

The laser transmitter of the A2D is based on an injection-seeded, frequency-tripled Nd:YAG master oscillator power amplifier (MOPA) system generating $30 \mathrm{~ns}$ output pulses at $354.89 \mathrm{~nm}$ wavelength. The laser provides $60 \mathrm{~mJ}$ pulse energy at $50 \mathrm{~Hz}$ repetition rate $(3.0 \mathrm{~W}$ average output power), while showing near-diffractionlimited beam quality $\left(\mathrm{M}^{2}<1.5\right)$. In addition to the strict requirements in terms of frequency stability, a further challenge is imposed by the fact that, due to a preparation time of the CCD detectors of the A2D receiver, the electronics have to be triggered $60 \mu \mathrm{s}$ before the laser pulse emission with an error of less than $100 \mathrm{~ns}$. Therefore, a dedicated active frequency stabilization technique was developed which is based on the RampDelay-Fire method [3]. Fast detection of the master oscillator cavity resonances with the seed laser frequency, combined with two adjustable delays, enabled accurate timing of the Q-switch trigger and effective compensation of higher-frequency vibrations, while providing a sufficiently early trigger for the detector electronics with a timing stability of around $80 \mathrm{~ns}$.

The resulting frequency stability of the A2D laser was evaluated under laboratory and vibration conditions in airborne operation, showing pulse-to-pulse fluctuations in the order $1.9 \mathrm{MHz}$ and $3.3 \mathrm{MHz}$, respectively (see Fig. 1a). The corresponding Allan deviations plots, depicted in Fig. 1b, indicate even lower mean frequency variations in the sub-MHz-regime on longer time scales of several seconds to minutes.

The A2D lidar system was recently successfully employed for wind profile measurements in an international aircraft field campaign conducted in Iceland in autumn 2016, yielding valuable data for the ADM-Aeolus satellite mission that is planned to be launched in December 2017.
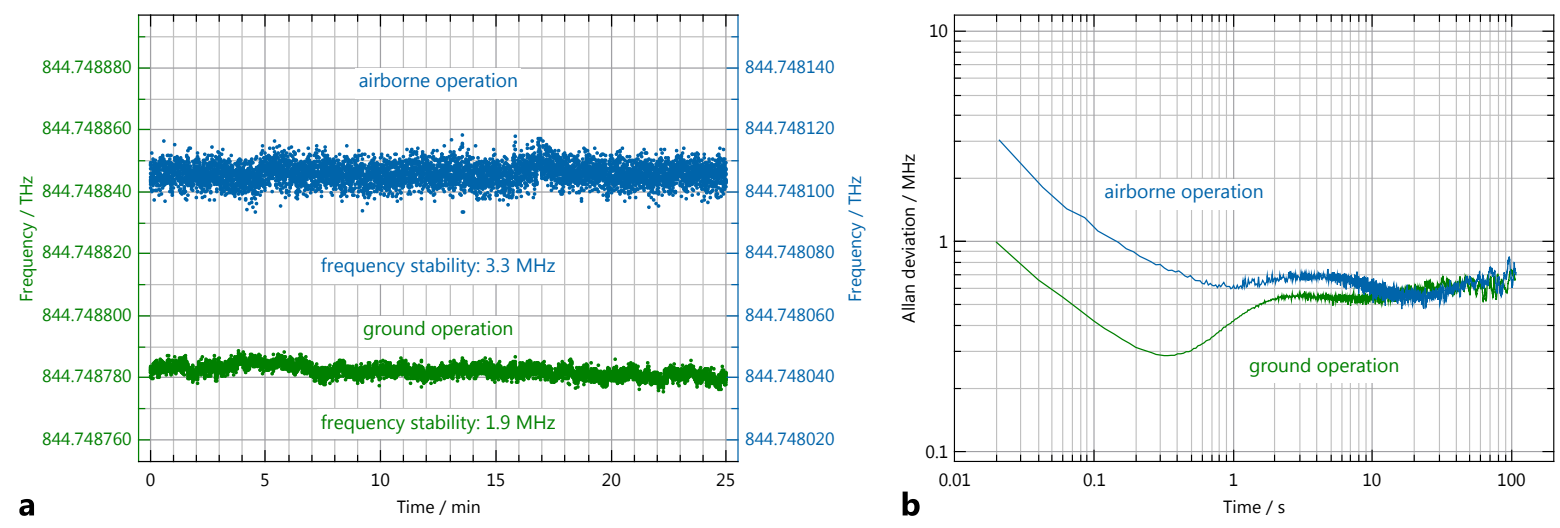

Fig. 1 a Frequency stability and $\mathbf{b}$ Allan deviation of the A2D laser transmitter in ground and airborne operation.

\section{References}

[1] O. Reitebuch, C. Lemmerz, E. Nagel, U. Paffrath, Y. Durand, M. Endemann, F. Fabre, and M. Chaloupy, "The Airborne Demonstrator for the Direct-Detection Doppler Wind Lidar ALADIN on ADM-Aeolus. Part I: Instrument Design and Comparison to Satellite Instrument," J. Atmos. Oceanic Technol. 26 (12), 2501 (2009).

[2] T. Schröder, C. Lemmerz, O. Reitebuch, M. Wirth, C. Wührer, and R. Treichel, "Frequency jitter and spectral width of an injectionseeded Q-switched Nd:YAG laser for a Doppler wind lidar," Appl. Phys. B 87 (3), 437 (2007).

[3] K. Nicklaus, V. Morasch, M. Hoefer, J. Luttmann, M. Vierkötter, M. Ostermeyer, J. Höffner, C. Lemmerz, and D. Hoffmann, "Frequency stabilization of Q-switched Nd:YAG oscillators for airborne and spaceborne lidar systems," Proc. SPIE 6451, 64511L (2007). 